
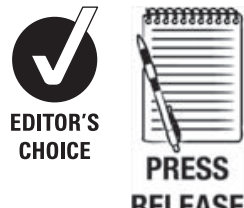

RELEASE

- Additional data are published online on

ly. To view the files please visit the journal online (http://adc.bmj.com/ content $/ 97 / 6$.toc)

${ }^{1}$ Children's Allergy Clinic, University Hospital Southampton NHS Foundation Trust, Southampton, UK

${ }^{2}$ School of Clinical Sciences, University of Bristol, Bristol, UK ${ }^{3}$ Clinical Sciences and Vaccine Institute, St. George's, University of London, London, UK ${ }^{4}$ School of Cellular and Molecular Medicine, University of Bristol, Bristol, UK

\section{Correspondence to} Dr Mich Lajeunesse, The Children's Allergy Clinic, University Hospital Southampton NHS

Foundation Trust, Tremona Road, Southampton S016 6YD, UK;

mich.lajeunesse@soton. ac.uk

Received 21 October 2011 Accepted 2 December 2011 Published Online First 23 January 2012

\title{
Anaphylaxis as an adverse event following immunisation in the UK and Ireland
}

\author{
Michel Erlewyn-Lajeunesse, ${ }^{1}$ Linda P Hunt, ${ }^{2}$ Paul T Heath, ${ }^{3}$ Adam Finn 2,4
}

\begin{abstract}
Anaphylaxis is a rare adverse event following immunisation (AEFI) and unlikely to be detected in prelicensure vaccine trials. Previous retrospective studies have been hampered by the paucity of information available to passive reporting schemes. The aim of the present study was to estimate the incidence and clinical presentation of anaphylaxis as an AEFI using prospective active surveillance.

Methods Children under 16 in the UK and Ireland with suspected anaphylaxis as an AEFI were reported through the British Paediatric Surveillance Unit (BPSU) between September 2008 and October 2009. Paediatricians completed questionnaires on presentation, diagnosis, management and outcome. Results A total of 7 out of 15 reports met criteria for anaphylaxis following immunisation. Four of the seven children reacted more than $30 \mathrm{~min}$ after administration of the vaccine. Six children required treatment with intramuscular adrenaline and intravenous fluids, but all made a full recovery. Denominators were not available for all vaccines so an overall incidence was not calculated, however the estimated incidence was 12.0 per 100000 dose for single component measles vaccine and 1.4 cases per million doses for the bivalent human papilloma virus vaccine (Cervarix, GSK).
\end{abstract}

Conclusions Anaphylaxis remains a rare adverse event following immunisation. No cases were related to vaccines given as part of the 'routine' infant and preschool immunisation programme, despite over 5.5 million vaccines being delivered in this time period. Some children had delayed onset of symptoms and this should be considered when vaccinating those at higher risk of anaphylaxis.

\section{INTRODUCTION}

Anaphylaxis is an acute hypersensitivity reaction, with multiorgan-system involvement, that can progress rapidly to a severe and life-threatening illness. ${ }^{1}$ There is no specific test and the diagnosis relies upon clinical symptoms and signs. Anaphylaxis may occur following exposure to allergens from a variety of sources including food, aeroallergens, venom, drugs and immunisations. Vaccines are a mixture of compounds, and an allergic sensitisation can occur to any component. Individuals may be sensitised to the vaccine antigen itself, an adjuvant such as alum, to excipient material used in the manufacturing process such as ovalbumin, gelatine and neomycin, or even to the latex stopper on the vial. ${ }^{23}$

Anaphylaxis as an adverse event following immunisation (AEFI) is rare. Even the largest prelicensure vaccine trials are unlikely to detect

\section{What is already known on this topic}

- Anaphylaxis is a rare adverse event following immunisation.

- Cases are difficult to ascertain using postmarketing surveillance.

- Cases occur soon after immunisation.

\section{What this study adds}

- No events were associated with infant and preschool schedule vaccinations.

- Some children had a delayed onset of symptoms and this should be considered when vaccinating those at high risk of anaphylaxis.

a single case, let alone provide an estimate of incidence. The onus for detection of anaphylaxis falls to national post-marketing surveillance (PMS) systems, all of which rely upon passive reporting of cases.

The aim of this study was to estimate the incidence and clinical presentation of anaphylaxis as an AEFI through prospective active surveillance using an internationally recognised case definition that would allow comparison with future studies.

\section{METHODS}

Children under 16 with suspected anaphylaxis AEFI were reported to the British Paediatric Surveillance Unit (BPSU) by paediatricians in the UK and Ireland. ${ }^{4}$ An 'orange card' with a list of rare disorders is sent to consultant paediatricians in the UK and Ireland each month. Clinicians return the card to the BPSU, notifying them of any cases or indicating 'nothing to report'. The study collected reports over 13 months between 1 September 2008 and 30 September 2009. Overall monthly return rates for BPSU cards were $93.2 \%$ in UK and $91.8 \%$ in Ireland during the study period.

Paediatricians were asked to report all children who may have experienced anaphylaxis following an immunisation, either presenting to them acutely or through clinic referral after the event. In order to capture all potential events we also requested cases where anaphylaxis was only suspected, but where further doses of vaccine were contraindicated. Reporting paediatricians 
completed online (Bristol Online Survey; http://www.survey. bris.ac.uk) or paper questionnaires on the case presentation, diagnosis, management and subsequent outcome.

The Brighton Collaboration Case Definition (BCCD) for anaphylaxis AEFI was used to define cases. ${ }^{5}$ The BCCD includes symptoms and signs arranged into major and minor criteria depending on sensitivity (as shown in table 1). The BCCD has three levels of diagnostic certainty, with level 1 being more specific and sensitive and level 3 remaining sensitive but with a relative loss in specificity (as shown in table 2).

The study was approved by the North Somerset and South Bristol National Research Ethics Service (ref: 07/H0106/119) and was granted Patient Information Advisory Group Section 60 support (ref: PIAG/BPSU 3-05(FT1)/2008).

\section{RESULTS}

In all, 15 reports were made to the study over 13 months. Seven cases met the BCCD for anaphylaxis as an AEFI. The presenting symptoms of anaphylaxis are shown in table 1 . All cases had some form of allergic rash as part of a multisystem presentation making other diagnoses such as panic attack and syncope less likely. Three cases met the BCCD at level 1 diagnostic certainty, three at level 2 and one case at level 3 (table 2). This latter case had been rapidly treated with adrenaline,

Table 1 Clinical presentation of anaphylaxis as an adverse event following immunisation (AEFI) using Brighton Collaboration Case Definition (BCCD). The table shows the reported symptoms and signs of anaphylaxis in the seven cases meeting BCCD with number of reports in brackets. The table is divided into major and minor Brighton criteria and all BCCD criteria are listed for completeness, even where no cases met the criteria ${ }^{5}$

\begin{tabular}{|c|c|c|}
\hline & Major & Minor \\
\hline $\begin{array}{l}\text { Dermatological and } \\
\text { mucosal }\end{array}$ & $\begin{array}{l}\text { Generalised } \\
\text { angioedema (2) } \\
\text { Local angioedema (1) } \\
\text { Rash and pruritus (1) } \\
\text { Generalised ery- } \\
\text { thema (2) } \\
\text { Generalised hives (5) }\end{array}$ & $\begin{array}{l}\text { Local hives }(1)^{*} \\
\text { Hives at injection site (1) } \\
\text { Generalised pruritus without } \\
\text { skin rash }(0) \\
\text { Generalised prickle sensa- } \\
\text { tion }(0) \\
\text { Red and itchy eyes }(0)\end{array}$ \\
\hline Cardiovascular & $\begin{array}{l}\text { Shock (1)† } \\
\text { Hypotension }(2) \ddagger\end{array}$ & $\begin{array}{l}\text { A reduced peripheral circu- } \\
\text { lation as indicated by the } \\
\text { combination of at least } 2 \text { of: } \\
\text { tachycardia (2); prolonged } \\
\text { capillary refill (1); decreased } \\
\text { consciousness (2) }\end{array}$ \\
\hline Respiratory & $\begin{array}{l}\text { Upper airway } \\
\text { angioedema (1) } \\
\text { Wheeze (1) } \\
\text { Respiratory } \\
\text { distress (1) } \\
\text { Stridor (0) }\end{array}$ & $\begin{array}{l}\text { Sneezing (1) } \\
\text { Sensation of throat closure (1) } \\
\text { Dyspnoea (3) } \\
\text { Cough (1) } \\
\text { Hoarse voice (0) }\end{array}$ \\
\hline Gastroenterological & Not applicable & $\begin{array}{l}\text { Nausea (1) } \\
\text { Vomiting (1) } \\
\text { Diarrhoea (0) } \\
\text { Abdominal pain (0) }\end{array}$ \\
\hline Laboratory & Not applicable & Raised serum tryptase (1)§ \\
\hline
\end{tabular}

*Localised hives were present in one case, but were not contributory to the BCCD.

tA clinical diagnosis of uncompensated shock was indicated by the combination of at least three of the following: tachycardia; capillary refill time $>3 \mathrm{~s}$; reduced central pulse volume; decreased level of consciousness or loss of consciousness.

¥Respiratory distress was defined by the presence of two or more of the following: tachypnoea; increased use of accessory respiratory muscles (sternocleidomastoid, intercostal, etc); recession; cyanosis; grunting. $\S$ A test for Mast Cell Tryptase (MCT) was only performed in one case, where it was raised $5 \mathrm{~h}$ after the reaction. which may have ameliorated disease progression and affected case ascertainment. ${ }^{6}$ Of the remaining cases, three were withdrawn by the reporting clinician and in four there was no further information available from the reporters; one report was of a hypotonic hyporesponsive episode. ${ }^{7}$ One case occurred outside of the study period and was not included in the incidence calculations.

Six of seven reporters of cases meeting the definition of anaphylaxis thought that the episode was causally related to immunisation. One reporter considered it was probably related; this was a case meeting level 2 BCCD that occurred 15-30 min after immunisation and required intramuscular adrenaline. One child had previously received a dose of the same vaccine without reaction, for the others it was their first exposure. Two children received several vaccines at the same visit. A number of different vaccines were implicated in these reactions: three human papilloma virus vaccines (HPV) (Cervarix, GlaxoSmithKline (GSK), Uxbridge, UK), two single component measles vaccines (Rouvax, Sanofi Pasteur MSD, Lyon, France), a meningococcal C conjugate vaccine, a school leaver's booster (probably tetanus/inactivated polio virus), an inactivated typhoid vaccine (Typhim Vi, Sanofi Pasteur MSD, Maidenhead, UK), a quadrivalent meningococcal polysaccharide vaccine (ACWY Vax, GlaxoSmithKline (GSK)) and a hepatitis A vaccine (Havrix Junior Monodose, GlaxoSmithKline (GSK)).

The onset of symptoms was within $15 \mathrm{~min}$ in three cases, but four episodes occurred $30 \mathrm{~min}$ or more following immunisation, and in one case 120 min after the event. Six children were treated with intramuscular adrenaline, three intravenous fluids and one salbutamol nebulisation. Only two received corticosteroids and five $\mathrm{H}_{1}$ histamine receptor inverse agonist. One child recovered without treatment. Three cases attended

Table 2 Diagnostic criteria for anaphylaxis as an adverse event following immunisation (AEFI). This table shows how the cases met Brighton Collaboration Case Definition (BCCD) criteria for anaphylaxis as an AEFI. ${ }^{5}$ The diagnosis rests upon the sudden onset and rapid progression of symptoms involving more than two organ systems. A case should also have at least one criterion from each designated system to meet the diagnosis

\begin{tabular}{|c|c|c|}
\hline $\begin{array}{l}\text { BCCD level } \\
\text { of diagnostic } \\
\text { certainty }\end{array}$ & Diagnostic criteria & $\begin{array}{l}\text { Number of cases } \\
\text { meeting criteria }\end{array}$ \\
\hline Level 1 & $\begin{array}{l}1 \text { major dermatological AND } \\
1 \text { major cardiovascular criterion } \\
1 \text { major dermatological AND } \\
1 \text { major respiratory criterion }\end{array}$ & $2 \dagger$ \\
\hline \multirow[t]{3}{*}{ Level 2} & $\begin{array}{l}1 \text { major cardiovascular AND } \\
1 \text { major respiratory criterion } \\
1 \text { major cardiovascular AND } \\
1 \text { minor criterion involving at least } \\
1 \text { different system (other than } \\
\text { cardiovascular system) }\end{array}$ & 1 \\
\hline & $\begin{array}{l}1 \text { major dermatological AND } \\
1 \text { minor cardiovascular criterion } \\
1 \text { major respiratory criterion AND } \\
1 \text { minor criterion involving at least } 1 \\
\text { different system (other than respiratory } \\
\text { system) }\end{array}$ & 0 \\
\hline & $\begin{array}{l}1 \text { major dermatological AND } \\
1 \text { minor respiratory criterion }\end{array}$ & 2 \\
\hline Level 3 & $\begin{array}{l}1 \text { minor cardiovascular OR respiratory } \\
\text { criterion AND at least } 1 \text { minor criterion } \\
\text { from each of two or more different } \\
\text { systems }\end{array}$ & 1 \\
\hline
\end{tabular}

tOne case had major respiratory and cardiovascular signs and met level 1 using both pathways. 
Emergency Medicine Departments, four required acute paediatric services and a further two were referred to paediatric outpatients after the event. No child was admitted to paediatric intensive care. All children made a full recovery without sequelae. Three children carried injectable adrenaline for preexisting atopic disease; one for multiple food allergies and two for idiopathic urticaria with anaphylaxis.

\section{Single component measles vaccines}

Two cases in this study were associated with single component measles vaccine. There were requests for 16625 doses of single measles vaccine to be imported over the study period (UK Medicines Healthcare products Regulatory Agency (MHRA), personal communication). This yields an incidence of 12.0 per 100000 doses.

\section{Human papilloma virus vaccines}

There were three cases associated with bivalent HPV with 2081272 doses (UK Cover of Vaccination Evaluated Rapidly (COVER) data) given between the ages of 12 to 19 years (the majority in children under 16) in the study period, which yields an incidence of 1.4 cases per million doses.

\section{DISCUSSION}

This study of anaphylaxis following immunisation in the UK and Ireland confirms that it is a rare adverse event. There were no reports of anaphylaxis following preschool and infant schedule vaccines, including measles, mumps and rubella (MMR) and influenza vaccines. Approximately 5.5 million infants received routine vaccines without any reported cases of anaphylaxis (table 3). This is extremely reassuring data for the general public and healthcare workers alike.

There are a limited number of studies specifically addressing the incidence of anaphylaxis as an AEFI. All cause anaphylaxis in the UK has been estimated at 8.4 per 100 000, of which $3.6 \%$ were reported following immunisation (2.9 per million population (not doses)). Ireland had no cases of anaphylaxis and nine reports of 'anaphylactoid' reactions reported to the Ireland Medical Board in the 5 years from 2000 to $2005 .{ }^{9}$ A US retrospective analysis of hospital discharge records identified

Table 3 Routine immunisation schedules during the study period. The table shows routine immunisation offered to all children from 1 September 2008 to 31 0ctober 2009. (Data from http://www. euvac.net, accessed 1 July 2011.)

\begin{tabular}{lll}
\hline Timing & UK & Ireland \\
\hline Birth & & BCG \\
2 Months & DTaP/IPV/Hib+PCV7 & DTaP/IPV/Hib/HBV+PCV7 \\
3 Months & DTaP/IPV/Hib+Men C & \\
4 Months & DTaP/IPV/Hib+PCV7+Men C & DTaP/IPV/Hib/HBV+Men C \\
6 Months & & DTaP/IPV/Hib/ \\
& & HBV+PCV7+Men C \\
12 Months & Hib/Men C & Hib+Men C \\
13 Months & MMR+PCV7 & MMR+PCV7 \\
4 Years & DTaP/IPV+MMR & DTaP/IPV+MMR \\
12-13 Years & HPV & \\
$13-18$ Years & Td/IPV & Td \\
\hline
\end{tabular}

BCG, bacillus calmette guerin vaccine; DTaP, diphtheria tetanus and acellular pertussis vaccine; HBV, hepatitis B virus vaccine; Hib, Haemophilus influenzae type b vaccine; HPV, human papiloma virus (bivalent) vaccine; IPV, inactivated polio virus vaccine; Men $C$, meningococcal $C$ conjugate vaccine; MMR, measles, mumps and rubella vaccine; PCV7, pneumococcal conjugate vaccine (seven valent); Td, tetanus with low dose diphtheria vaccine. five cases of anaphylaxis in 7.5 million doses of vaccine, yielding an incidence of 0.65 cases per million doses. ${ }^{10}$ In two of these five 'cases', one was atypical and one was doubtful. This study exemplifies the difficulty in describing anaphylaxis as an AEFI in any detail using retrospective analyses. The US Vaccine Adverse Event Reporting System (VAERS; http://vaers.hhs.gov) recorded 452 reports of 'anaphylactoid reactions' in over 1.9 billion doses of vaccine administered countrywide over a 10 year period..$^{11}$ This yields an estimated incidence of 0.2 cases per million doses, which is close to the MHRA (http://www.mhra.gov.uk) estimate of one in a million doses. ${ }^{12}$

The absence of a total for all vaccines given during this period meant that we were unable to calculate an overall incidence. However we were able to provide an estimate for two vaccines.

\section{Single component measles vaccines}

Two cases were associated with single component measles vaccine while there were no reports of anaphylaxis to $M M R$. Unlike the MMR, there is no central reporting mechanism for administration of this non-routine schedule vaccine (which may contribute up to $2 \%$ of measles immunity). ${ }^{13}$ Our calculated incidence of 12 per 100000 doses compares with no reports from approximately 750000 (690000 UK, 60000 Ireland) doses of MMR given to children under 2 in the UK and Ireland, with at least a further 600000 having a further MMR booster dose by 4 years in the same period. A higher rate of anaphylaxis following single component vaccines has been previously observed, although there is no obvious explanation for this. ${ }^{14}$ Measures should be taken to record the use of non-routine vaccines so that the public may be protected. ${ }^{13}$

\section{Human papilloma virus vaccines}

Our calculated anaphylaxis incidence for HPV vaccine of 1.4 cases per million doses is considerably lower than that seen with a quadrivalent HPV vaccine in Australia. ${ }^{15}$ Most of the Australian quadrivalent HPV reactions were idiosyncratic. ${ }^{16}$ Our study observed that several children already carried adrenaline autoinjectors for idiopathic anaphylaxis or multiple food allergies, which would suggest that their response was also idiosyncratic. We suggest that children with idiopathic anaphylaxis are immunised in a centre used to treating anaphylaxis and are observed for at least an hour following the procedure.

\section{Onset of reaction}

We noted that four episodes occurred more than $30 \mathrm{~min}$ after the immunisation. This has been observed in other studies and is in keeping with an idiosyncratic non-immunoglobulin $\mathrm{E}$ mediated reaction. ${ }^{161718}$ There is no standard observation time post vaccination, although $20 \mathrm{~min}$ is observed in many centres. ${ }^{19}$ Given the rarity of anaphylaxis as an AEFI it is impractical to suggest lengthening this time window. However, for children at higher risk of reaction, for example those with a previous history of idiopathic anaphylaxis, a longer observation time of up to 60 min may be appropriate in keeping with allergen immunotherapy practice. ${ }^{20}$

\section{Limitations of the study}

The BPSU has an established method for research into rare diseases without patient consent (through exemption by Section 60 of the Health and Social Care Act); As a consequence no 
attributable information can be published. For very rare disorders, the methodology has limitations, as patient confidentiality takes precedent over the ability to clearly report clinical data. Data such as ours would normally be presented as a case series, but without individual patient consent, we were unable to do so.

Despite its limitations the small numbers of cases reported are likely to be a true estimate of anaphylaxis AEFI rates. Although the majority of immunisation occurs in primary care, a paediatrician will probably have reviewed all severe reactions. In general, acute referral to hospital for anaphylaxis occurs $60 \%$ to $70 \%$ of the time, but this may be higher for vaccine related events where healthcare professionals have been recently involved in the child's care. ${ }^{8}$

Finally, it has been suggested that the BCCD used in this study may overestimate numbers of cases, although subsequent validation has shown it to be as accurate as other consensus definitions. ${ }^{1521}$

\section{Reimmunisation}

This study did not consider the safety of reimmunisation following anaphylaxis as an AEFI. Although further vaccination with the same vaccine is routinely contraindicated, in many cases children can be safely reimmunised following a hypersensitivity reaction. ${ }^{22}$ There are now comprehensive guidelines for subsequent immunisation following an allergic adverse event. ${ }^{23}$ We recommend that reimmunisation should be assessed and conducted only in experienced centres.

\section{CONCLUSIONS}

Anaphylaxis remains a very rare adverse event following immunisation. There is a clear need for international surveillance using standardised methodologies and case definitions. ${ }^{6}$ No events were related to routine infant and preschool immunisations despite over 5.5 million primary schedule vaccines being delivered in this time period. Some children had delayed onset of symptoms and this should be considered in those at higher risk of anaphylaxis. All children responded promptly to treatment and there were no deaths or long term effects reported.

Acknowledgments The authors would like to thank the clinicians who reported cases, Alan Sheridan, Graham Matthews, MHRA; Suzanne Cotter, Eire COVER; Nick Andrews and Joanne White of UK COVER for help with vaccine coverage data, and Professor Alan Emond, Chair BPSU for his comments on the manuscript and support for this study. The authors acknowledge the BPSU, supported by the Department of Health (DH), for facilitating the data collection and the reporting clinicians, particularly those who completed the questionnaires. Any views expressed (in publications) are those of the investigator(s) and not necessarily those of the BPSU or DH.

Funding This study was funded by an unrestricted educational grant from Sanofi Pasteur MSD.

Competing interests MEL has received reimbursement to attend scientific meetings from GSK and Wyeth. PTH is an investigator for clinical trials conducted on behalf of St. George's, University of London, sponsored by vaccine manufacturers. Industry-sourced honoraria for consultancy are paid to an educational/administrative fund held by St. George's, University of London. AF undertakes clinical trials and related research, consultancy, lecturing and chairing for all the major vaccine manufacturers and has received reimbursement of travel, accommodation, registration and living expenses related to these activities. All honoraria and research funding are paid either to the University of Bristol or University Hospitals NHS Foundation Trust.

Ethics approval North Somerset and South Bristol National Research Ethics Service.

Provenance and peer review Not commissioned; externally peer reviewed.

\section{REFERENCES}

1. Sampson HA, Muñoz-Furlong A, Campbell RL, et al. Second symposium on the definition and management of anaphylaxis: summary report-Second National Institute of Allergy and Infectious Disease/Food Allergy and Anaphylaxis Network symposium. J Allergy Clin Immunol 2006;117:391-7.

2. Madaan A, Maddox DE. Vaccine allergy: diagnosis and management. Immunol Allergy Clin North Am 2003;23:555-88.

3. Pool V, Braun MM, Kelso JM, et al. Prevalence of anti-gelatin IgE antibodies in people with anaphylaxis after measles-mumps rubella vaccine in the United States. Pediatrics 2002;110:e71.

4. Lynn R, Ross E. The British Paediatric Surveillance Unit: the first 20 years. Arch Dis Child 2007:92:744-5.

5. Rüggeberg JU, Gold MS, Bayas JM, et al. Anaphylaxis: case definition and guidelines for data collection, analysis, and presentation of immunization safety data. Vaccine 2007;25:5675-84.

6. Erlewyn-Lajeunesse M, Bonhoeffer J, Ruggeberg JU, et al. Anaphylaxis as an adverse event following immunisation. J Clin Pathol 2007;60:737-9.

7. Buettcher M, Heininger U, Braun M, et al. Hypotonic-hyporesponsive episode (HHE) as an adverse event following immunization in early childhood: case definition and guidelines for data collection, analysis, and presentation. Vaccine 2007;25:5875-81.

8. Peng MM, Jick H. A population-based study of the incidence, cause, and severity of anaphylaxis in the United Kingdom. Arch Intern Med 2004;164:317-19.

9. Llewellyn M. Anaphylaxis following paediatric immunization. Ir Med J 2006;99:125.

10. Bohlke K, Davis RL, Marcy SM, et al. Risk of anaphylaxis after vaccination of children and adolescents. Pediatrics 2003;112:815-20.

11. Zhou W, Pool V, Iskander JK, et al. Surveillance for safety after immunization: Vaccine Adverse Event Reporting System (VAERS)-United States, 1991-2001. MMWR Surveill Summ 2003:52:1-24.

12. Department of Health. Vaccine safety and the mangement of adverse events following immunisation. Immunisation Against Infectious Disease. Department of Health 2006:53-64.

13. Sonnenberg $\mathbf{P}$, Crowcroft NS, White JM, et al. The contribution of single antigen measles, mumps and rubella vaccines to immunity to these infections in England and Wales. Arch Dis Child 2007;92:786-9.

14. Erlewyn-Lajeunesse M, Manek R, Lingam R, et al. Anaphylaxis following single component measles and rubella immunisation. Arch Dis Child 2008;93:974-5.

15. Brotherton JM, Gold MS, Kemp AS, et al. Anaphylaxis following quadrivalent human papillomavirus vaccination. CMAJ 2008;179:525-33.

16. Kang LW, Crawford N, Tang ML, et al. Hypersensitivity reactions to human papillomavirus vaccine in Australian schoolgirls: retrospective cohort study. BMJ 2008:337:a2642

17. Patja A, Davidkin I, Kurki T, et al. Serious adverse events after measles-mumpsrubella vaccination during a fourteen-year prospective follow-up. Pediatr Infect Dis J 2000;19:1127-34.

18. Nakayama T, Onoda K. Vaccine adverse events reported in post-marketing study of the Kitasato Institute from 1994 to 2004. Vaccine 2007;25:570-6.

19. Salisbury D. Immunisation Against Infectious Disease. Fourth edition. London: TSO 2006:25:570-6

20. Erlewyn-Lajeunesse M, Brathwaite N, Lucas JS, et al. Recommendations for the administration of influenza vaccine in children allergic to egg. BMJ 2009;339:b3680.

21. Erlewyn-Lajeunesse M, Dymond S, Slade I, et al. Diagnostic utility of two case definitions for anaphylaxis: a comparison using a retrospective case notes analysis in the UK. Drug Saf 2010;33:57-64

22. Gold M, Goodwin H, Botham S, et al. Re-vaccination of 421 children with a past history of an adverse vaccine reaction in a special immunisation service. Arch Dis Child 2000;83:128-31.

23. Wood RA, Berger M, Dreskin SC, et al. An algorithm for treatment of patients with hypersensitivity reactions after vaccines. Pediatrics 2008;122:e771-7. 